\title{
Startup Helps Military Spouses be Successful Entrepreneurs
}

\section{Kimberly Eddleston (Northeastern University)}

KEYWORDS: Entrepreneurship, Women.

Military families often must move every three years, making it nearly impossible for spouses to sustain a career that requires working for someone else. Many smart and talented spouses are becoming entrepreneurs, a path that allows them to thrive professionally even when they can't stay in one place. They are launching retail businesses, delivery services and consultancies. One organization, the Association of Military Spouse Entrepreneurs, is connecting these entrepreneurs with the resources they need to be successful. In this interview, familybusiness.org editor Kimberly Eddleston talks with AMSE co-founders Moni Jefferson and Flossie Hall, both successful entrepreneurs in their own right, about how they are helping military spouses and what it takes to build a viable, scalable and easily portable business. Some key takeaways: don't be afraid to take the leap, learn from failure, and ask for help. 